\title{
Quantification of bovine viral diarrhoea virus ribonucleic acid in serum of infected animals by one-step reverse transcriptase quantitative real-time polymerase chain reaction
}

\author{
Věra Fichtelová, Kamil Kovařčík \\ Veterinary Research Institute, Department of Virology, Brno, Czech Republic
}

Received March 25, 2019

Accepted October 29, 2019

\begin{abstract}
Bovine viral diarrhoea virus (BVDV) can cause either acute transient or persistent infection. Identification and removal of persistently infected animals from infected herds is a crucial component to control BVDV infection. Only limited data on serum virus concentration in infected animals are available to date. Using one-step reverse transcriptase quantitative real-time polymerase chain reaction, we quantified the serum viral load in 40 BVDV infected animals. To control nucleic acid extraction, complementary DNA synthesis and polymerase chain reaction amplification, each serum sample was spiked with a known small amount of reference canine coronavirus. Detected ribonucleic acid copy number ranged from $2.2 \times 10^{6}$ to $7.4 \times 10^{8}$ per $1 \mathrm{ml}$ of serum of persistently infected animals and from $6.6 \times 10^{4}$ to $3.3 \times 10^{7}$ of transiently infected animals. These findings support the idea that it is impossible to accurately distinguish between transiently and persistently infected animals just from a single blood sample. To use this testing as a means of declining costs of BVDV control programmes cannot be recommended and paired serum samples have to be investigated to confirm persistent infection.
\end{abstract}

Reverse transcription quantitative PCR, ruminant

Bovine viral diarrhoea virus (BVDV) is a member of the Pestivirus genus within the Flaviviridae family. Bovine viral diarrhoea viruses form two separate species, BVDV 1 and BVDV 2 which are further divided into several genetic subtypes. Pestiviruses are small enveloped viruses that contain single stranded positive sense RNA of approximately $12.5 \mathrm{~Kb}$ in length. The viral genome consists of a single open reading frame, flanked at both ends with short untranslated regions (5'UTR, 3'UTR). The ORF encodes one polyprotein which is subsequently cleaved into 12 individual viral proteins. According to the presence or absence of the cytopathic effect on cultured epithelial cells, BVDVs are divided into two different biotypes, cytopathic (cp) and noncytopathic (ncp).

Bovine viral diarrhoea is one of the most economically important diseases of cattle worldwide. Bovine viral diarrhoea virus infection can produce a broad range of clinical signs from mild to lethal mucosal disease or can infect animals without any obvious signs of disease. Bovine viral diarrhoea virus causes either acute transient (TI) or persistent (PI) infection (Baker 1995). The virus first replicates in epithelial cells of the affected mucosa and surrounding lymphoid tissue, which is followed by the spread to regional lymph nodes, viraemia and dissemination of the virus throughout the body (Howard 1990; Marshall et al. 1996; Bruschke et al. 1998). Acute infection results in short-term transient viraemia. Thereafter, the virus is cleared by the host immune system and specific antiviral antibodies are detected. In pregnant viraemic animals, the virus can cross the placenta and infect the foetus. Persistent infection develops when foetuses are exposed to ncp biotype of BVDV before they are immuno-competent on day 120 of gestation. This leads to a lack of recognition of viral antigens by the host immune system, persistent viraemia and replication of the virus to high titres in all tissues and organs (Ohmann 1988). Persistently infected

Address for correspondence: 
animals shed large amounts of virus in most secretions and excretions into the environment and are a major source of the infectious virus for their herd mates.

Identification and removal of PI animals from infected herds is a crucial component to control BVDV infection (Lindberg and Alenius 1999; Letellier et al. 2005; Lindberg and Houe 2005; Houe et al. 2006). Serum samples are widely used to identify PI animals (Saliki and Dubovi 2004; Sandvik 2005). Nowadays, viral antigens and/or viral RNA are detected in serum samples by antigen ELISA (enzyme-linked immunosorbent assay) and RT-PCR (reverse transcription polymerase chain reaction) or quantitative RT-qPCR. The RT-PCR has more advantages as it is not affected by the presence of antiviral antibodies and is also more sensitive than antigen ELISA. Pooled serum samples are investigated by PCR to reduce the costs of identification of PI individuals (Munoz-Zanzi et al. 2000; Mars and van Maanen 2005; Laureyns et al. 2010).

The aim of our study was to quantify and evaluate serum viral load in BVDV infected animals by the RT-qPCR targeting the 5'UTR genome region and employing hydrolysis probes.

\section{Materials and Methods}

Serum samples

The serum samples were collected during a voluntary BVDV control/eradication program conducted in the Czech Republic in 2009-2011. To identify PI animals, animals older than 6 months were screened for antibodies using a commercially available ELISA kit (BVD-MD IgG ELISA, Test-line, Brno, Czech Republic). Thereafter, the antibody-negative animals were tested for virus by antigen ELISA (BVDV Antigen Test Kit/Serum Plus, IDEXX, Bern, Switzerland). The antibody-negative virus-positive animals were retested at least 3 weeks apart. Repeated detection of viral antigen in antibody-negative cattle confirmed PI. On the contrary, seroconversion proved transient BVDV infection. A total of 77 serum samples from 40 infected animals were tested to quantify viral RNA (Table 1). Serum samples were stored at $-80^{\circ} \mathrm{C}$ until processed and used in RT-qPCR.

RNA extraction

Viral RNA was extracted from $140 \mu \mathrm{l}$ of serum samples using QIAamp Viral RNA kit (Qiagen, Hilden, Germany). Immediately before RNA extraction, the serum samples were spiked with $10 \mu 1$ of Canine Coronavirus $(\mathrm{CCoV})$ strain 1-71 (ATCC VR-809, Collection of Animal Pathogenic Microorganisms, VúveL, Brno, Czech Republic) representing 9.5 median tissue culture infective dose (TCID50) The amounts of reagents added to the sample before loading onto QIAamp spin columns were then proportionally increased as recommended by the supplier. RNA was eluted in a volume of $60 \mu \mathrm{l}$ and extracted RNA samples were stored until used in RT-qPCR at $-80^{\circ} \mathrm{C}$.

Primers and probe

Sequences of primers and probe were selected from 5'UTR of the BVDV genome and were based on primers and probe designed previously by Mahlum et al. (2002) and Young et al. (2006), respectively. After alignment of 226 sequences deposited in the GenBank, degeneracy was incorporated into specific nucleotide sites of forward (BVDV 183-F) and reverse (BVDV 343-R) primer. Both primers and probe (P-BVDV-224) were further lengthened to increase their melting temperatures. Details of primers and probe are shown in Table 2. The primers and probes were synthesized by Generi Biotech s. r. o., Hradec Králové, Czech Republic.

Synthesis of RNA standard for RT-qPCR

A 160 bp fragment of 5'UTR of BVDV 1 (CZ3192) amplified by RT-PCR using primers 183-F and 343-R was separated on 1.5\% agarose gel and purified using a Gel Extraction kit (Qiagen, Hilden, Germany). Purified cDNA was cloned into pGEM (Promega, Madison, USA). Plasmid was linearized and purified using QIAquick PCR purification kit (Qiagen, Hilden, Germany). Purified linearized plasmid served as a template for in vitro transcription by T7 RNA polymerase (Promega, Madison, USA). RNA transcript was treated with RQ1 RNase-Free DNAse (Promega, Madison, USA) to remove plasmid DNA and purified by RNeasy kit (Qiagen, Hilden, Germany). The RNA transcript was dissolved in nuclease-free water and quantified using NanoDrop 2000 spectrophotometer and converted into copy number. RT-qPCR was performed with 10-fold serial dilution $\left(10^{11}-10^{0}\right.$ RNA copies per reaction).

\section{RT-qPCR for BVDV quantification}

The reverse transcription and PCR was performed in a single tube using QuantiTect Probe RT-PCR kit (Qiagen, Hilden, Germany). Reaction mix recipes were prepared according to the manufacturer's instructions with a final reaction volume of $10 \mu \mathrm{l}$. The reaction mixture consisted of: $5 \mu \mathrm{l}$ of $2 \times$ QuantiTect Probe RT-PCR Master Mix, 
Table 2. Nucleotide sequences and location of the polymerase chain reaction primers and hydrolysis probes used in this study.

\begin{tabular}{llrc}
\hline & Sequence (5'-3') & Genome position & Amplicon length \\
\hline Primer name & & $183-204^{\mathrm{a}}$ & $160 \mathrm{bp}$ \\
BVDV 183-F & ACAGGGNAGTCGTCARTGGTTC & $320-343^{\mathrm{a}}$ & \\
BVDV 343-R & CTCTGCWRCACCCTATCAGGCTGT & $724-745^{\mathrm{b}}$ & $147 \mathrm{bp}$ \\
& & $849-871^{\mathrm{b}}$ & \\
CCoV N724-F & CACACCTGGAAGAGAACTGCAG & & \\
CCoV N871-R & CAGATGGAACACATTCAGCCAGT & $224-254^{\mathrm{a}}$ & \\
\hline Probe name & & $816-846^{\mathrm{b}}$ & \\
P-BVDV 224 & FAM-CTCGAGATGCCAYGTGGACGAGGGCATGCC-BHQ1 & \\
P-CCoV N816 & FAM-TGCCAATGGKARCAGTGCCAAGCATTACCCA-BHQ1 & \\
\hline
\end{tabular}

$\mathrm{BVDV}=$ bovine viral diarrhoea virus; $\mathrm{CCoV}=$ canine coronavirus; $\mathrm{A}=$ adenine; $\mathrm{T}=$ thymine; $\mathrm{C}=$ cytosine; $\mathrm{G}=$ guanine; $\mathrm{N}=$ any base; $\mathrm{R}=$ adenosine or guanine; $\mathrm{W}=$ adenine or thymine; $\mathrm{bp}=$ base pair; $\mathrm{FAM}=$ carboxyfluorescein; BHQ1 = black hole quencher $1 ;^{\mathrm{a}}=$ position relative to BVDV strain NADL (GenBank Accession number AJ133739); ${ }^{\mathrm{b}}=$ position relative to $\mathrm{CCoV}$ isolate 1-71 (GenBank Accession number AB105373)

$1 \mu \mathrm{M}$ forward primer 183-F, $1 \mu \mathrm{M}$ reverse primer 343-R, $0.2 \mu \mathrm{M}$ probe P-BVDV-224, $0.1 \mu 1$ of QuantiTect RT Mix and $2 \mu 1$ of template. The assay was carried out in white LightCycler 480 Multiwell Plates 96 (Roche, Mannheim, Germany) and was run in LightCycler 480 Instrument (Roche, Mannheim, Germany). The thermocycling consisted of reverse transcription at $50{ }^{\circ} \mathrm{C}$ for $20 \mathrm{~min}$, PCR initial activation step at $95{ }^{\circ} \mathrm{C}$ for $15 \mathrm{~min}$, followed by 45 two-step cycles of denaturation at $95^{\circ} \mathrm{C}$ for $30 \mathrm{~s}$ and combined annealing/extension at $60{ }^{\circ} \mathrm{C}$ for $60 \mathrm{~s}$. Fluorescence signals were measured during the elongation step.

\section{CCoV reference and CCoV RT-qPCR}

The specific amplification and detection of CCoV RNA was performed in a separate RT-qPCR reaction. The RT-qPCR mastermix and thermocycling conditions were the same as for BVDV RT-qPCR. The primers (forward CCoV N724-F and reverse CCoV N871-R) and probe (P-CCoV N816) were selected from the nucleoprotein gene of CCoV 1-71 sequence AB105373 obtained from the GenBank. Details of primers and probes are listed in Table 2 .

\section{Sequencing}

Primers BD1 and BD3 (Vilcek et al. 2001) were used to partially sequence the $\mathrm{N}^{\text {pro }}$ protein gene of BVD viruses from infected animals 34, 35, 36, 37 and 38. Viral RNA was transcribed and amplified by a Transcriptor One-Step RT-PCR kit (Roche, Meinnheim, Germany) according to the manufacturer's instructions. Fifty $\mu 1$ of reaction mixture consisted of $10 \mu \mathrm{l}$ of $5 \times$ Reaction Buffer, $0.4 \mu \mathrm{M}$ of both forward and reverse primers, $1 \mu 1$ of Transcriptor Enzyme mix and $5 \mu \mathrm{l}$ of template. The resulting PCR products were gel purified using a Gel Extraction kit (Qiagen, Hilden, Germany) and afterwards sent to Eurofins Genomics (Vienna, Austria) for sequencing.

\section{Results}

\section{Linearity and limit of detection of BVDV RT-qPCR}

A standard curve was established using standard BVDV RNA that was 10-fold serially diluted from $1 \times 10^{10}$ to $1 \times 10^{2}$ copies per reaction and amplified in duplicate. The standard curve showed an efficiency of 1.91, a correlation coefficient of 0.999 , a slope of -3.56 , and an intercept of 42.23 . The assay was linear over a range of $1 \times 10^{2}$ to $1 \times 10^{10}$ RNA copies and detected at least 100 RNA copies.

\section{RT-qPCR normalisation}

Tenfold serial dilutions of CCoV viral stock $\left(9.5 \times 10^{5}\right.$ TCID50) were extracted and tested in duplicate in CCoV RT-qPCR. The concentration of 9.5 TCID50 (quantification cycle (Cq) value above 30) was chosen to normalize BVDV RT-qPCR. To evaluate precision and reproducibility of the assay, 80 spiked serum samples were amplified and the mean $\mathrm{Cq}$ and SD obtained were 31.67 and 0.4 , respectively. 


\section{BVDV quantification}

The concentration of BVDV RNA copies was determined only for samples in which $\mathrm{Cq}$ values for $\mathrm{CCoV}$ reference ranged between $31.67 \pm 0.4$. Samples in which $\mathrm{CCoV} \mathrm{Cq}$ values were outside this range were retested and repeated; detection of Cq value above or below the threshold ranges excluded samples from quantification $(\mathrm{n}=10)$. A standard curve was established for each RT-qPCR run and individual standard curves showed efficiency between 1.8 and 1.9 and regression coefficient above 1.99. RNA copy numbers from $2.2 \times 10^{6}$ to $7.4 \times 10^{8}$ per $\mathrm{ml}$ were detected in serum samples of $37 \mathrm{PI}$ animals and from $6.6 \times 10^{4}$ to $3.3 \times 10^{7}$ in 3 acutely infected animals (Table 1 ).

\section{Sequencing}

Sequences obtained during the study were deposited in the GenBank under their accession numbers (MK410569-73). The 381 bp nucleotide long partial sequences of the $\mathrm{N}^{\text {pro }}$ protein gene were identical except one synonymous substitution detected in the sequence of BVDV from PI animal 34 (data not shown).

\section{Discussion}

We used one-step RT-qPCR utilizing a hydrolysis probe to quantify BVDV RNA in serum samples. For monitoring sample processing and amplification efficiency, a known amount of reference virus was added to each serum sample at the beginning of the isolation procedure (Cleland et al. 1999; Niesters 2001; Castelain et al. 2004; Young et al. 2006; Ward et al. 2009). Whenever the efficiency of RT-qPCR is inhibited and/or RNA is lost during sample processing, the $\mathrm{Cq}$ of reference virus will be higher. Thus the presence of amplifiable RNA as well as of inhibitory substances in extracted material is simultaneously monitored by this method.

In our study, sera of young animals aged between 6-12 months were collected, each animal was sampled twice during the time period ranging from 21 days up to 2 months to confirm PI. A relatively stable value of BVDV concentration was detected among sera from first and second sampling. The viral load ranging from $2.2 \times 10^{6}$ to $7.4 \times 10^{8} \mathrm{RNA}$ copy number per $\mathrm{ml}$ was detected in serum of PI animals by RT-qPCR. Serum load levels of $3.3 \times 10^{7}, 1.8 \times 10^{7}$, and $6.6 \times 10^{4}$ RNA copy number of BVDV were detected in acutely infected animals 37,38 , and 39 , respectively (Table 1). As the virus replicates to high titres in PI animals, it is generally supposed that PI animals have a higher concentration of BVDV in their sera than acutely infected animals have. Only the serum viral load of three TI animals was quantified in our study. These animals tested positive for viral RNA and antigen in the first sampling and were antibody positive three weeks apart, which confirmed transient infection. The PI animals $(34,35$, and 36) housed together with TI animals in the same herd $\mathrm{G}$ had serum viral loads ranging from $6.6 \times 10^{6}$ to $1.3 \times 10^{7}$ and these values are comparable with the viral load of $3.3 \times 10^{7}$ and $1.8 \times 10^{7}$ of TI animals 37 and 38, respectively. This is in accordance with the results obtained by antigen ELISA where corrected optical density (OD) of TI and PI reached similar values (data not shown). On the contrary, in TI animal 39, the viral serum load of $6.6 \times 10^{4}$ was significantly lower and the corrected OD value in antigen ELISA was also lower, which together with no detection of antiviral antibodies suggests the beginning of infection. Hanon et al. (2012) tested whole blood samples with commercial real-time RT-PCR test and found that the mean Cq value for PI animals is much lower than for TI. Nevertheless, they also detected TI animals with the same or even lower Cq value than the Cq value of some PI animals was. They also detected TI animals which tested positive by antigen ELISA. These results agree with our findings that the serum viral load in acutely infected animals can reach the same value as in PI animals. 
Table 1. Quantification of bovine viral diarrhoea virus ribonucleic acid copies in 1 millilitre of serum by reverse transcriptase quantitative polymerase chain reaction.

Herd A

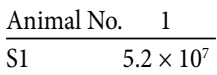

S2 $\quad \mathrm{x}$

Herd B

\begin{tabular}{lcccccccccc} 
Animal No. & 2 & 3 & 4 & 5 & 6 & 7 & 8 & 9 & 10 & 11 \\
\hline S1 & $3.9 \times 10^{7}$ & $1.8 \times 10^{7}$ & $5.1 \times 10^{7}$ & $5.9 \times 10^{7}$ & $8.6 \times 10^{7}$ & $6.0 \times 10^{7}$ & $3.3 \times 10^{8}$ & $\mathrm{x}$ & $\mathrm{x}$ & $1.8 \times 10^{7}$ \\
S2 & $1.4 \times 10^{7}$ & $2.5 \times 10^{7}$ & $6.5 \times 10^{7}$ & $2.3 \times 10^{7}$ & $9.2 \times 10^{7}$ & $4.7 \times 10^{7}$ & $3.8 \times 10^{8}$ & $2.0 \times 10^{7}$ & $9.3 \times 10^{7}$ & $\mathrm{x}$
\end{tabular}

Herd C

\begin{tabular}{lcc} 
Animal No. 12 & 13 \\
\hline S1 & $6.0 \times 10^{6}$ & $7.5 \times 10^{6}$
\end{tabular}

S2 $\quad 5.6 \times 10^{6} \quad 6.1 \times 10^{6}$

Herd D

\begin{tabular}{lllrc} 
Animal No. 14 & 15 & 16 & 17 \\
\hline S1 & $2.7 \times 10^{7}$ & $1.8 \times 10^{8}$ & $\mathrm{x}$ & $9.5 \times 10^{7}$
\end{tabular}

S2 $\quad 2.6 \times 10^{7} \quad 4.1 \times 10^{7} \quad 4.2 \times 10^{7} \quad \mathrm{x}$

Herd E

\begin{tabular}{lcccccccccc} 
Animal No. & 18 & 19 & 20 & 21 & 22 & 23 & 24 & 25 & 26 & 27 \\
\hline S1 & $4.3 \times 10^{7}$ & $3.1 \times 10^{7}$ & $6.5 \times 10^{7}$ & $6.7 \times 10^{7}$ & $9.2 \times 10^{7}$ & $1.8 \times 10^{8}$ & $6.3 \times 10^{7}$ & $1.7 \times 10^{8}$ & $7.4 \times 10^{8}$ & $1.7 \times 10^{8}$ \\
S2 & $8.3 \times 10^{7}$ & $6.8 \times 10^{7}$ & $4.6 \times 10^{7}$ & $5.4 \times 10^{7}$ & $6.5 \times 10^{7}$ & $1.3 \times 10^{8}$ & $4.3 \times 10^{7}$ & $1.7 \times 10^{8}$ & $3.1 \times 10^{8}$ & $1.4 \times 10^{8}$
\end{tabular}

Herd F

\begin{tabular}{lcccccc} 
Animal No. 28 & 29 & 30 & 31 & 32 & 33 \\
\hline S1 & $2.5 \times 10^{8}$ & $2.9 \times 10^{8}$ & $1.7 \times 10^{8}$ & x & x & $3.4 \times 10^{7}$
\end{tabular}

$\begin{array}{lllllll}\text { S2 } & 2.1 \times 10^{8} & 2.6 \times 10^{8} & \text { x } & 6.0 \times 10^{7} & 1.6 \times 10^{8} & \text { x }\end{array}$

Herd G

\begin{tabular}{lcccccc} 
Animal No. & 34 & 35 & 36 & 37 & 38 & 39 \\
\hline S1 & $6.6 \times 10^{6}$ & $1.9 \times 10^{7}$ & $1.3 \times 10^{7}$ & $3.3 \times 10^{7}$ & $1.8 \times 10^{7}$ & $6.6 \times 10^{4}$ \\
S2 & $2.2 \times 10^{6}$ & $1.1 \times 10^{7}$ & $9.2 \times 10^{6}$ & ND & ND & ND
\end{tabular}

Herd $\mathrm{H}$

Animal No. 40

$\begin{array}{ll}\text { S1 } & 1.5 \times 10^{8} \\ \text { S2 } & 6.4 \times 10^{7}\end{array}$

Animal No. = animal number; $\mathrm{S} 1=$ first sampling; $\mathrm{S} 2$ = second sampling taken at least 3 weeks apart from the first sampling; $\mathrm{x}=$ quantification cycle of canine coronavirus out of range of $31.67 \pm 0.4$; bovine viral diarrhoea virus ribonucleic acid copy number not quantified; $\mathrm{ND}=$ not done 
To characterize BVD viruses in the infected PI and TI animals from herd G (animals 34, $35,36,37$ and 38), we partially sequenced their $\mathrm{N}^{\text {pro }}$ protein gene. The obtained $381 \mathrm{bp}$ long nucleotide sequences were identical except for one synonymous substitution detected in the sequence of BVDV from PI animal 34, suggesting that TI and PI animals were infected with the same virus and our results are not affected by viral strain variations.

Our results further revealed that the variability of virus concentration among different herds was more considerable than among animals in one herd. There are herds with relatively higher (herd E, mean viral load level $1.5 \times 10^{8} \mathrm{RNA} / \mathrm{ml}$ ) or lower (herd $\mathrm{C}$, mean viral load $6.3 \times 10^{6} \mathrm{RNA} / \mathrm{ml}$ ) serum viral loads. The variability of virus concentration in serum between individual PI animals in one herd mostly does not exceed one order of magnitude. To answer the question whether the variability of BVDV serum concentration revealed among PI animals is due to different viral strains infecting them, sequence analysis should be performed.

In summary, we detected that serum viral load in PI animals $\left(2.2 \times 10^{6}\right.$ to $7.4 \times 10^{8} \mathrm{RNA}$ copy number per $\mathrm{ml})$ can reach the same value as in TI animals $\left(6.6 \times 10^{4} ; 1.8 \times 10^{7}\right.$, and $3.3 \times 10^{7}$. Data of the present study revealed that it is not possible to use virus quantification in serum samples to distinguish between persistently and transiently infected animals and paired serum samples should always be investigated to confirm persistent infection.

\section{Acknowledgements}

This work was supported by grant No. QI101A094 from the Ministry of Agriculture and by the Ministry of Education, Youth and Sports of the Czech Republic (project LO1218 under NPU-I program).

\section{References}

Baker JC 1995: The clinical manifestations of bovine viral diarrhea infection. Vet Clin North Am Food Anim Pract 11: 425-445

Bruschke CJ, Weerdmeester K, Van Oirschot JT, Van Rijn PA 1998: Distribution of bovine virus diarrhoea virus in tissues and white blood cells of cattle during acute infection. Vet Microbiol 64: 23-32

Castelain S, Descamps V, Thibault V, Francois C, Bonte D, Morel V, Izopet J, Capron D, Zawadzki P, Duverlie G 2004: TaqMan amplification system with an internal positive control for HCV RNA quantitation. J Clin Virol 31: $227-234$

Cleland A, Nettleton P, Jarvis L, Simmonds P 1999: Use of bovine viral diarrhoea virus as an internal control for amplification of hepatitis C virus. Vox Sang 76: 170-174

Hanon JB, Van der Stede Y, Antonissen A, Mullender C, Tignon M, van den Berg, Caij B 2014: Distinction between persistent and transient infection in bovine viral diarrhoea (BVD) control programme: appropriate interpretation of real-time RT-PCR and Antigen-ELISA test results. Transbound Emerg Dis 61: 156-162

Houe H, Lindberg A, Moennig V 2006: Test strategies in bovine viral diarrhea virus control and eradication campaigns in Europe. J Vet Diagn Invest 18: 427-436

Howard CJ 1990: Immunological responses to bovine virus diarrhoea virus infection. Rev Sci Tech 9: 95-103

Laureyns J, Ribbens S, de Kruif A 2010: Control of bovine virus diarrhoea at the herd level: reducing the risk of false negatives in the detection of persistently infected cattle. Vet J 184: 21-26

Letellier C, De Meulemeester L, Lomba M, Mijten E, Kerkhofs P 2005: Detection of BVDV persistently infected animals in Belgium: Evaluation of the strategy implemented. Prev Vet Med 72: 121-125

Lindberg AL, Alenius S 1999: Principles for eradication of bovine viral diarrhoea virus (BVDV) infections in cattle populations. Vet Microbiol 64: 197-222

Lindberg A, Houe H 2005: Characteristics in the epidemiology of bovine viral diarrhea virus (BVDV) of relevance to control. Prev Vet Med 72: 55-73

Mahlum CE, Haugerud S, Shivers JL, Rossow KD, Goyal SM, Collin JE, Faaberg KS 2002: Detection of bovine viral diarrhea virus by TaqMan reverse transcription polymerase chain reaction. J Vet Diag Inves 14: 120-125

Mars MH, Van Maanen C 2005: Diagnostic assays applied in BVDV control in The Netherlands. Prev Vet Med 72: $43-48$

Marshall DJ, Moxley RA, Kelling CL 1996: Distribution of virus and viral antigen in specific pathogen-free calves following inoculation with noncytophatic bovine viral diarrhea virus. Vet Pathol 33: $311-318$

Munoz-Zanzi CA, Johnson WO, Thurmond MC, Hietala SK 2000: Pooled-sample testing as a herd-screening tool for detection of bovine viral diarrhea virus persistently infected cattle. J Vet Diagn Invest 12:195-203

Niesters HG 2001: Quantitation of viral load using real-time amplification techniques. Methods 25: 419-429 
Ohmann HB 1988: BVD virus antigens in tissues of persistently infected viraemic, clinically normal cattle: implication for the pathogenesis of clinically fatal disease. Acta Vet Scand 29: 77-84

Saliki JT, Dubovi EJ 2004: Laboratory diagnosis of bovine viral diarrhea virus infections. Vet Clin North Am Food Anim Pract 20: 69-83

Sandvik T 2005: Selection and use of laboratory diagnostic assays in BVD control programmes. Prev Vet Med 72: 3-16

Vilcek S, Paton DJ, Durkovic B, Strojny L, Ibata G, Moussa A., Loitsch A, Rossmanith W, Vega S, Scicluna MT, Palfi V 2001: Bovine viral diarrhoea virus genotype 1 can be separated into at least eleven genetic groups. Arch Virol 146: 99-115

Young NJ, Thomas CJ, Collins ME, Brownlie J 2006: Real-time RT-PCR detection of Bovine Viral Diarrhoea virus in whole blood using an external RNA reference. J Virol Methods 138: 218-222

Ward P, Poitras E, Leblanc D, Letellier A, Brassard J, Plante D, Houde A 2009: Comparative analysis of different TaqMan real-time RT-PCR assays for the detection of swine Hepatitis E virus and integration of Feline calicivirus as internal control. J Appl Microbiol 106: 1360-1369 